\title{
INTEGRATED DEWATERING SYSTEM (IDS)
}

\author{
Lesti Herawati $A^{1)}$, Rolando $A^{1)}$ \\ ${ }^{1)}$ Mine Hydorolgy Expert, PT. Pamapersada Nusantara
}

\begin{abstract}
ABSTRAK
Dalam bisnis proses penambangan batubara dengan metode penambangan Open Pit Mining, dewatering menjadi salah satu kunci sukses keberhasilan operasional penambangan. Oleh karena itu proses perencanaan, eksekusi, monitoring dan evaluasi dewatering wajib dilaksanakan dengan baik. Sebagai salah satu aktivitas kritikal, dewatering memerlukan proses monitoring yang baik untuk mencapai Excellence Dewatering dan cost dewatering yang efisien. Terlebih di era digital seperti saat ini, proses monitoring dewatering yang real time, cepat, akurat, komprehensif dan terintegrasi mutlak diperlukan. Digitalisasi monitoring dewatering dengan "Integrated Dewatering System" (IDS) menjadi solusi atas challenge untuk monitoring dewatering yang excellence. Integrated Dewatering System (IDS) : Suatu sistem Dewatering yang terintegrasi dalam pengumpulan, pengolahan \& penyajian data secara real time sehingga dapat digunakan sebagai dasar analisa \& pengambilan keputusan yang cepat \& tepat guna mewujudkan tambang No Flood dengan Cost Dewatering yang efisien. Cakupan area monitoring IDS meliputi : curah hujan, sump, pompa. Hardware IDS yaitu : Weather Station alat untuk mengukur curah hujan, durasi hujan, frekuensi hujan secara real time; 2) Automatic Flowmeter alat untuk mengukur debit pompa secara otomatis dan real time; 3) Automatic Water Level alat untuk mengukur elevasi sump (area tampungan air di pit), sehingga elevasi sump dapat dimonitor secara real time. Secara umum proses monitoring Dewatering dengan IDS adalah sebagai berikut : weather station mengukur curah hujan (mm), durasi hujan (menit), frekuensi hujan, data curah hujan kemudian dilakukan proses perhitungan untuk menghitung volume run off yang masuk ke tambang, air yang masuk ke dalam sump secara berkesinambungan dipompa, debit pemompaan diukur dengan menggunakan automatic flowmeter, selanjutnya automatic water level mengukur elevasi sump, kemudian sistem akan mengolah data-data output dalam software IDS yang kemudian menyampaikan Alert melalui media mobile phone informasi status sump sebagai Early Warning untuk memberikan "guidance corrective action" terhadap kondisi dewatering yang terjadi. Manfaat dari IDS yaitu : 1) Proses monitoring curah hujan, debit pompa dan elevasi air lebih cepat, mudah; 2) Data monitoring Dewatering akurat dan terintegrasi; 3) Memberikan Early Warning terhadap status sump sehingga corrective action yang tepat dan cepat dapat segera dilaksanakan; 4) Mencegah tambang Flood dengan corrective action yang cepat, 5) Meningkatkan aspek Safety karena high risk activity berkurang; 6) Cost dewatering efisien dengan operasional pompa (debit, Rotary Per Minutes, Utilization Availability) yang optimum.
\end{abstract}

Kata kunci : IDS, weather station, automatic flowmeter, automatic water level

\begin{abstract}
In the business of coal mining using the Open Pit Mining method, dewatering is one of the keys to the success of mining operations. Therefore the process of planning, execution, monitoring and evaluation of dewatering must be carried out properly. As one of the critical activities, dewatering requires a good monitoring process to achieve Excellence Dewatering and cost-efficient dewatering. Especially in the digital era as it is today, real-time, fast, accurate, comprehensive and integrated dewatering monitoring process is absolutely necessary. The digitization of dewatering monitoring with the "Integrated Dewatering System" (IDS) is the solution to the challenge for excellence dewatering monitoring. Integrated Dewatering System (IDS): A Dewatering system that is integrated in the collection, processing \& presentation of data in real time so that it can be used
\end{abstract}


as a basis for analysis \& decision making that is fast \& precise in order to realize the No Flood mine with an efficient Cost Dewatering. The scope of the IDS monitoring area includes: rainfall, sumps, pumps. IDS hardware namely: 1) Weather Station tool to measure rainfall, duration of rain, frequency of rain in a Manner real time; 2) Automatic Flowmeter tool to measure pump flow automatically and in real time; 3) Automatic Water Level tool to measure the elevation of the sump (water catchment area in the pit), so that the sump elevation can be monitored in real time. In general the Dewatering monitoring process with IDS is as follows: weather station measures rainfall (mm), duration of rain (minutes), frequency of rainfall, rainfall data then the calculation process is carried out to calculate the volume of run-off entering the mine, water entering in a sump continuously pumped, pumping discharge is measured using automatic flowmeter, then automatic water level measures the elevation of the sump, then the system will process the output data in the IDS software which then conveys the "Alert" through the mobile phone media sump status information as an Early Warning for provide "guidance corrective action" for conditions of dewatering that occur. Benefits of IDS are: 1) The process of monitoring rainfall, pump discharge and water elevation is faster, easier; 2) Dewatering monitoring data is accurate and integrated; 3) Give an Early Warning on the status of the sump so that corrective action is appropriate and quickly can be implemented immediately; 4) Prevent Flood mining with fast corrective action; 5) Improve the Safety aspect because of the reduced high risk activity; 6) Cost-efficient dewatering with pump operations (discharge, Rotary Per Minutes, Utilization Availability) is optimum.

Keywords: IDS, weather station, automatic flow meter, automatic water level

\section{A. PENDAHULUAN}

Dalam bisnis proses penambangan batubara dengan metode penambangan Open Pit Mining, dewatering menjadi salah satu kunci sukses keberhasilan operasional penambangan. Karena jika pengelolaan air tidak dilaksanakan dengan baik maka dapat menyebabkan target produksi tidak tercapai karena area kerja tergenang. Terlebih dengan kondisi area tambang yang semakin dalam dan luas, monitoring dewatering menjadi tantangan yang memerlukan solusi yang tepat (Gambar $1)$.

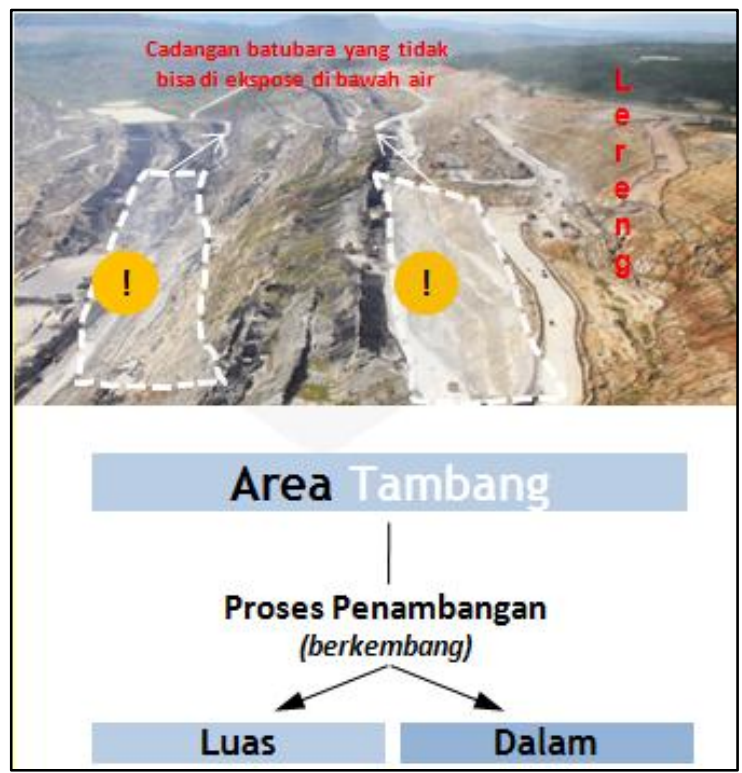

Gambar 1. Area tambang yang luas dan dalam. 
Sebagai salah satu aktivitas kritikal, dewatering memerlukan proses perencanaan, eksekusi, monitoring dan evaluasi yang baik untuk mencapai Excellence Dewatering dan cost dewatering yang efisien. Di era digital seperti saat ini proses proses monitoring dewatering yang real time, cepat, akurat, komprehensif dan terintegrasi mutlak diperlukan. Digitalisasi monitoring dewatering dengan "Integrated Dewatering System" (IDS) menjadi solusi atas challenge untuk monitoring dewatering yang excellence.

Integrated Dewatering System (IDS) adalah Suatu sistem Dewatering yang terintegrasi dalam pengumpulan, pengolahan \& penyajian data secara real time sehingga dapat digunakan sebagai dasar analisa \& pengambilan keputusan yang cepat \& tepat guna mewujudkan tambang No Flood dengan Cost Dewatering yang efisien. Cakupan area monitoring IDS meliputi : curah hujan, sump, pompa.

Adapun latar belakang proses development "Integrated Dewatering System" (IDS) adalah sebagai berikut :

1. Adanya kebutuhan operasional untuk monitoring proses dewatering secara cepat, akurat dan terintegrasi.

2. Pengelolaan air yang masuk ke dalam tambang dengan cepat dan tepat memerlukan teknologi dalam proses monitoring.

3. Kebutuhan efisiensi cost dalam aktifitas dewatering dengan tindakan pengambilan keputusan yang cepat dan tepat dan perencanaan, monitoring dewatering.

Tujuan proses development IDS adalah :

1. Untuk memperoleh data output dewatering, meliputi : curah hujan, elevasi sump, debit pompa yang akurat.

2. Mempermudah dan mempercepat proses monitoring curah hujan, elevasi sump, debit pompa.

3. Digitalisasi proses monitoring dewatering yaitu : pengukuran curah hujan, pengukuran debit pompa dan pengukuran elevasi air.

4. Untuk melaksanakan "Excellent Dewatering Monitoring" dengan corrective action yang lebih cepat.

5. Mempercepat pengambilan keputusan untuk meminimalisir kerugian secara finansial dan waktu kerja dengan corrective action yang cepat dilaksanakan ketika terjadi deviasi.

Dalam proses monitoring dewatering terdapat tantangan yang memerlukan solusi.

1. Proses pengukuran data curah hujan untuk menghitung volume air masuk tambang menggunakan alat ukur curah hujan manual (Gambar 2.) dan memerlukan "Man Power" dengan metode pengambilan data setiap hari pada periode : 24 jam. Data output alat ukur curah hujan berupa akumulasi curah hujan harian (mm).

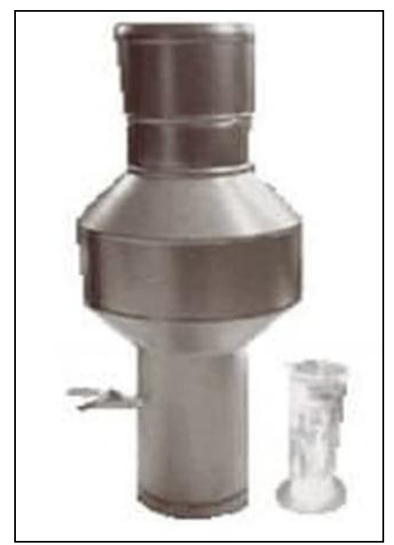

Gambar 2 : Alat Ukur Curah Hujan Manual 
Akurasi data curah hujan yang diperoleh yang rendah karena waktu pengambilan data curah hujan tidak selalu pada jam yang sama setiap hari. Selain akurasi data, kebutuhan akan data durasi hujan dan frekuensi hujan yang akurat menjadi kebutuhan untuk perencanaan, monitoring proses operasional lapangan. Saat ini terdapat teknologi yaitu alat ukur curah hujan otomatis atau sering disebut "Weather Station". Pendekatan pemecahan masalah dilaksanakan dengan automatisasi pengukuran data curah hujan, durasi hujan dan frekuensi hujan untuk memperoleh data yang akurat, real time tanpa memerlukan "Man Power."

2. Proses pengukuran debit pompa untuk menghitung volume air yang dikeluarkan dari sump dilakukan manual dengan alat "Flowbar" (Gambar 3.) memerlukan orang khusus, dan hanya dilakukan setiap 12 jam. Hal ini menyebabkan data debit pompa (m3/jam) tidak akurat dan berpengaruh pada perhitungan volume air yang dipompa tidak tepat.

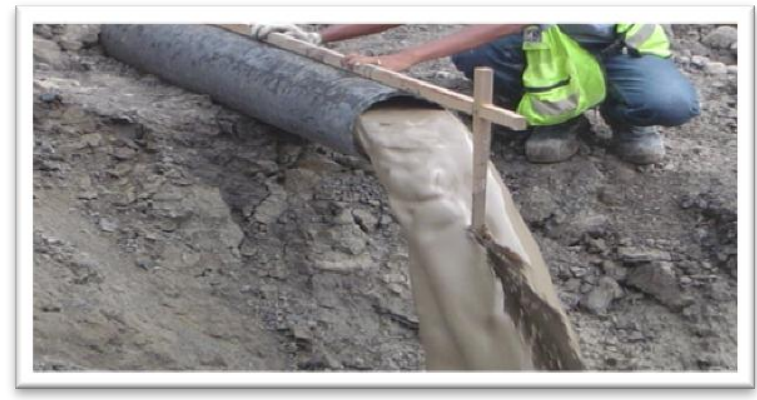

\section{Gambar 3 : Alat Ukur Debit Manual dengan Flowbar}

Pendekatan pemecahan masalah dilaksanakan dengan penggunaan alat ukur debit otomatis/ automatic flowmeter sehingga pengukuran debit pompa akurat, real time dan dapat diketahui jam kerja pompa secara otomatis. Dengan automatic flowmeter volume air yang dipompa dapat diketahui dengan cepat, dan akurat Data output Automatic flowmeter (Gambar 4) dikirim ke dalam Software IDS. Selain itu dengan pemasangan flowmeter pada line pipa maka problem pada pompa dapat segera diketahui sehingga perbaikan dapat dilakukan lebih cepat.

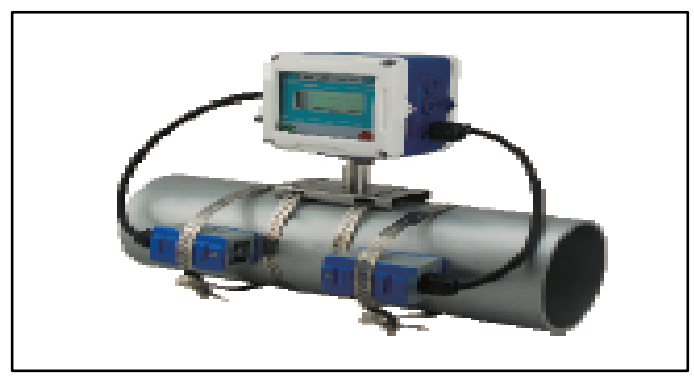

Gambar 4. Alat Ukur Debit Digital Automatic Flowmeter

3. Pengukuran elevasi sump menggunakan GPS yang dilakukan oleh Crew Survey dengan waktu pelaksanaan pengukuran yang tidak selalu sama setiap hari (Gambar 5). Kebutuhan data water balance yang tepat adalah periode pengukuran data curah hujan, elevasi sump pada jam yang sama (1 jam sekali atau 24 jam sekali). Aktual di lapangan pada saat crew survey melakukan pengukuran curah hujan, maka data elevasi sump tidak bisa diukur karena orang yang melakukan aktifitas tersebut adalah orang yang sama.

Pendekatan pemecahan masalah pengukuran elevasi sump dilaksanakan dengan mengganti alat ukur elevasi sump yang sebelumnya menggunakan General Position System (GPS) dan diukur oleh crew survey (Gambar 4.) dengan pemasangan GPS di sump agar data elevasi 
sump dapat diukur oleh GPS (Gambar 6.) dan secara online data elevasi sump terkirim ke dalam sistem IDS.

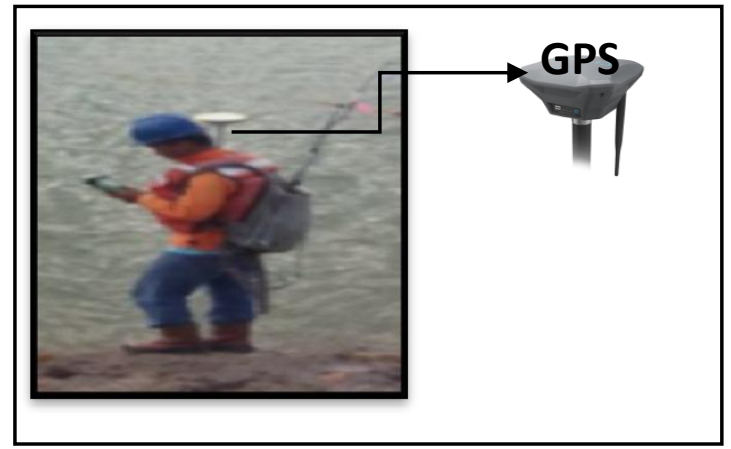

Gambar 5 : Pengukuran elevasi sump oleh Crew Survey dengan GPS

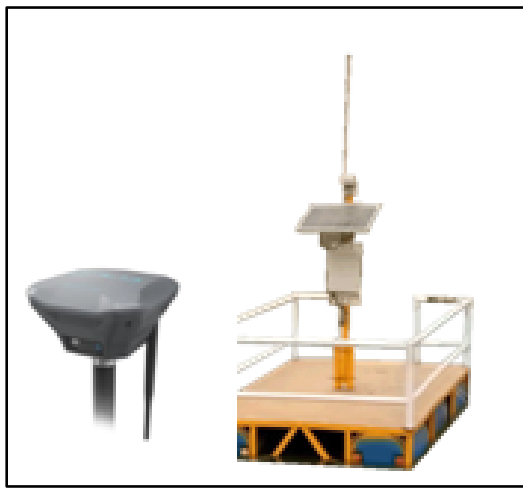

Gambar 6. GPS dipasang di sump di dekat pompa

Secara garis besar pengukuran data monitoring dewatering dapat digambarkan sebagai berikut (Tabel 1) :

Tabel 1. Peralatan Monitoring Dewatering

\begin{tabular}{llcc}
\hline \multicolumn{1}{c}{ Peralatan } & Fambar & Output \\
\hline \hline Alat Ukur Curah Hujan Manual & $\begin{array}{c}\text { Mengukur data curah } \\
\text { hujan }\end{array}$ & Curah hujan (mm) \\
Flowbar & Mengukur debit pompa & Debit (m ${ }^{3} /$ jam) \\
GPS & Mengukur elevasi sump & Elevasi Sump (ML) \\
\hline
\end{tabular}




\section{B. METODOLOGI PENELITIAN}

Metodologi penelitian merupakan sebuah cara untuk mengetahui hasil dari sebuah permasalahan yang spesifik, dimana permasalahan tersebut disebut juga dengan permasalahan penelitian."Metodologi", itu adalah cara mencari atau memecahkan masalah penelitian. (Sumber : https://www.statistikian.com/2016/11/metodologi-penelitian.html/amp).

- Jenis Penelitian

Berdasarkan jenis penelitian proses monitoring dewatering dengan menggunakan IDS merupakan Penelitian Deskriptif merupakan metode yang bertujuan untuk membuat deskripsi secara sistematis, faktual, serta akurat pada fakta dengan metode pengumpulan data-data untuk menguji dugaan awal untuk menjawab pertanyaan penelitian. Berdasarkan jenis data, penelitian ini termasuk penelitian kuantitatif. Penelitian kuantitatif adalah penelitian yang datanya merupakan data kuantitatif sehingga analisis datanya menggunakan analisis kuantitatif (inferensi). Data kuantitatif adalah dalam bentuk angka, atau data kualitatif yang diangkakan. (sumber: http://konsultasiskripsi.com).

- Jenis dan Sumber Data

Proses monitoring dewatering IDS menggunakan jenis data yang data primer : data ouput curah hujan dari alat ukur curah hujan manual, data debit pompa output dari flowbar, data elevasi sump output GPS yang dilakukan oleh crew survey. Dan data sekunder merupakan data yang diperoleh atau dikumpulkan peneliti dari berbagai sumber yang ada (peneliti sebagai tangan kedua). Data primer dan data sekunder pada penelitian ini merupakan data project IDS yang diambil dan dimiliki oleh perusahaan kontraktor pertambangan, PT Pamapersada Nusantara.

- Teknik / Metode Analisis Data

Penelitian monitoring dewatering dengan IDS menggunakan metode yang digunakan dalam analisis data dalam penelitian ini adalah deskriptif kuantitatif. Penelitian ini merupakan penelitian yang bertujuan menjelaskan fenomena yang ada dengan menggunakan angkaangka untuk mencandarkan karakteristik individu atau kelompok (Syamsudin \& Damiyanti: 2011). Penelitian ini mengukur dan menghitung data curah hujan dengan alat ukur curah hujan manual dan dibandingkan dengan data pengukuran menggunakan alat Weather station dengan membandingkan data output alat ukur curah hujan manual dengan Weather Station. Dari hasil pengukuran data diketahui bahwa dengan menggunakan Weather Station diperoleh data curah hujan yang akurat, cepat dan diperoleh data-data output lain yaitu : durasi hujan, frekuensi hujan dimana data-data ini tidak dapat diperoleh jika pengukuran dilaksanakan dengan alat ukur curah hujan manual. Metode penelitian juga dilaksanakan dengan mengukur data debit pompa dan dilakukan pengolahan deta dengan Flowbar untuk kemudian dibandingkan pengukuran data menggunakan automatic flowmeter. Berdasarkan hasil analisa data diketahui bahwa dengan menggunakan flowbar akurasi data rendah dan data debit hanya dapat diketahui setiap 12 jam, dengan menggunakan Automatic Flowmeter data debit pompa akurat, dapat diperoleh dengan cepat, online dan data durasi pemompaan dapat diketahui dengan tepat.

Teknik analisis data elevasi sump dilakukan dengan mengukur data elevasi oleh Crew Survey dimana diperoleh data elevasi sump setiap 24 jam sekali dan mengukur data elevasi sump dengan output data dari pemasangan GPS di sump yang berupa data elevasi sump per periode waktu sesuai kebutuhan. Proses instalasi hardware IDS dilaksanakan sesuai dengan hasil analisa (Gambar 7).

\section{HASIL DAN PEMBAHASAN}

Berdasarkan penelitian yang dilaksanakan diperoleh hasil sebagai berikut : 
a. Automatisasi proses Monitoring dewatering meliputi data curah hujan, data debit pompa dan elevasi sump yang tersampaikan dengan dashboard dewatering.

b. Digitalisasi proses monitoring dewatering sehingga data monitorting dewatering real time sehingga proses pengambilan keputusan dan corrective action lebih cepat dan akurat.
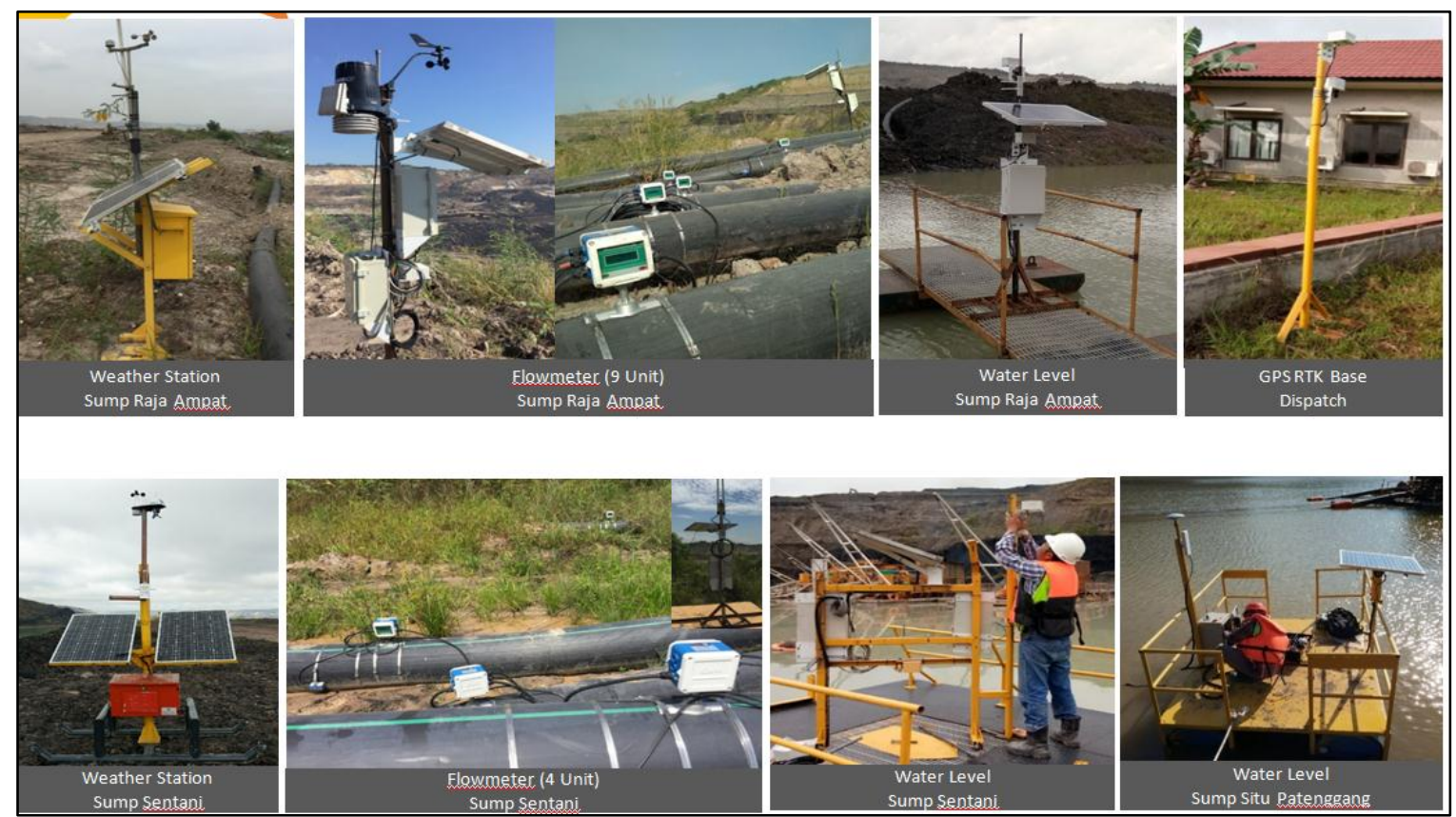

Gambar 7. Proses Instalasi hardware IDS

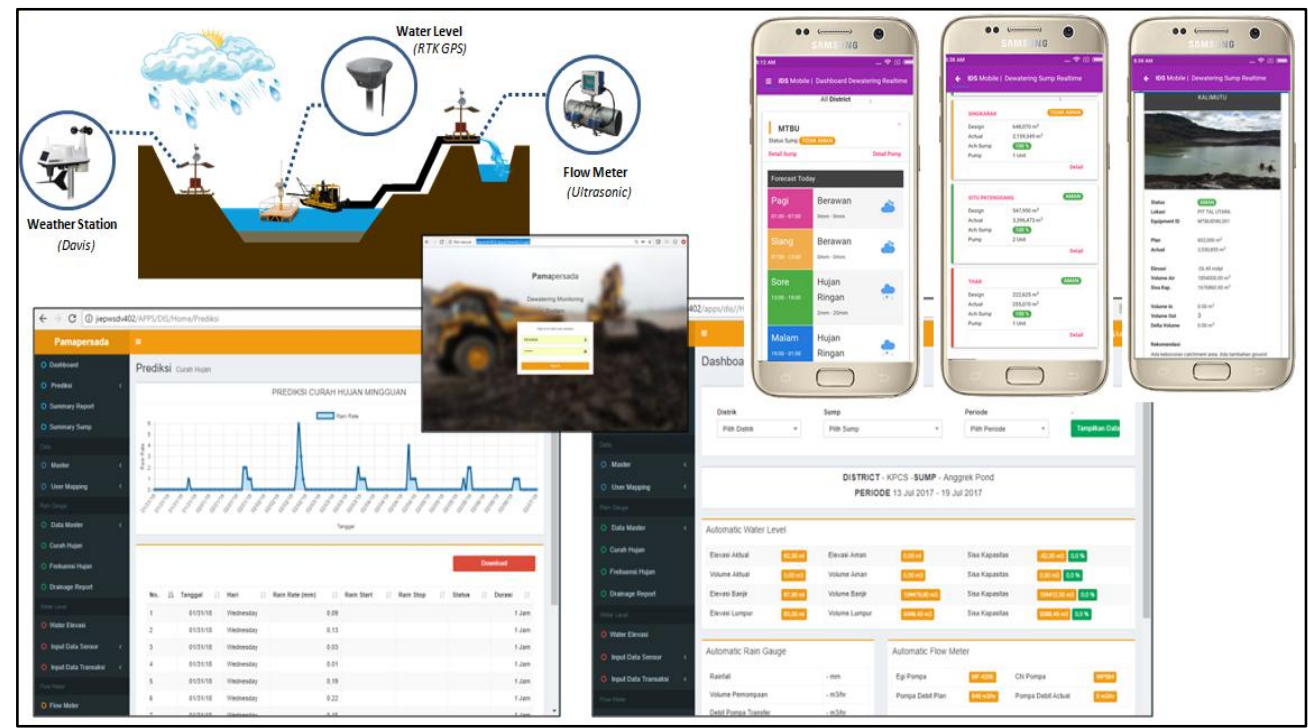

Gambar 8. Skema IDS \& Report IDS

c. Setelah kurang lebih 1 tahun melaksanakan perbaikan dan efisiensi, pama berhasil menghemat investasi pompa sebesar $\$ 2.961 .000$, setara dengan 9 unit MF420EXHV. Serta berhasil menghemat biaya pengadaan jalur pipa HDPE 355 sepanjang 2000 meter sebesar \$107.357. 
d. Dengan monitoring dewatering maka PAMA mendapat Voice of Customer dari salah satu Owner Penanbangan yang menunjukkan kepuasan Owner terhadap proses monitoring dewatering." : "Kemajuan dewatering PAMA sangat luar biasa. Hal ini dapat menjadi contoh bagi kontraktor yang lain.(Budi Rachman, COO PT Adaro Indonesia)

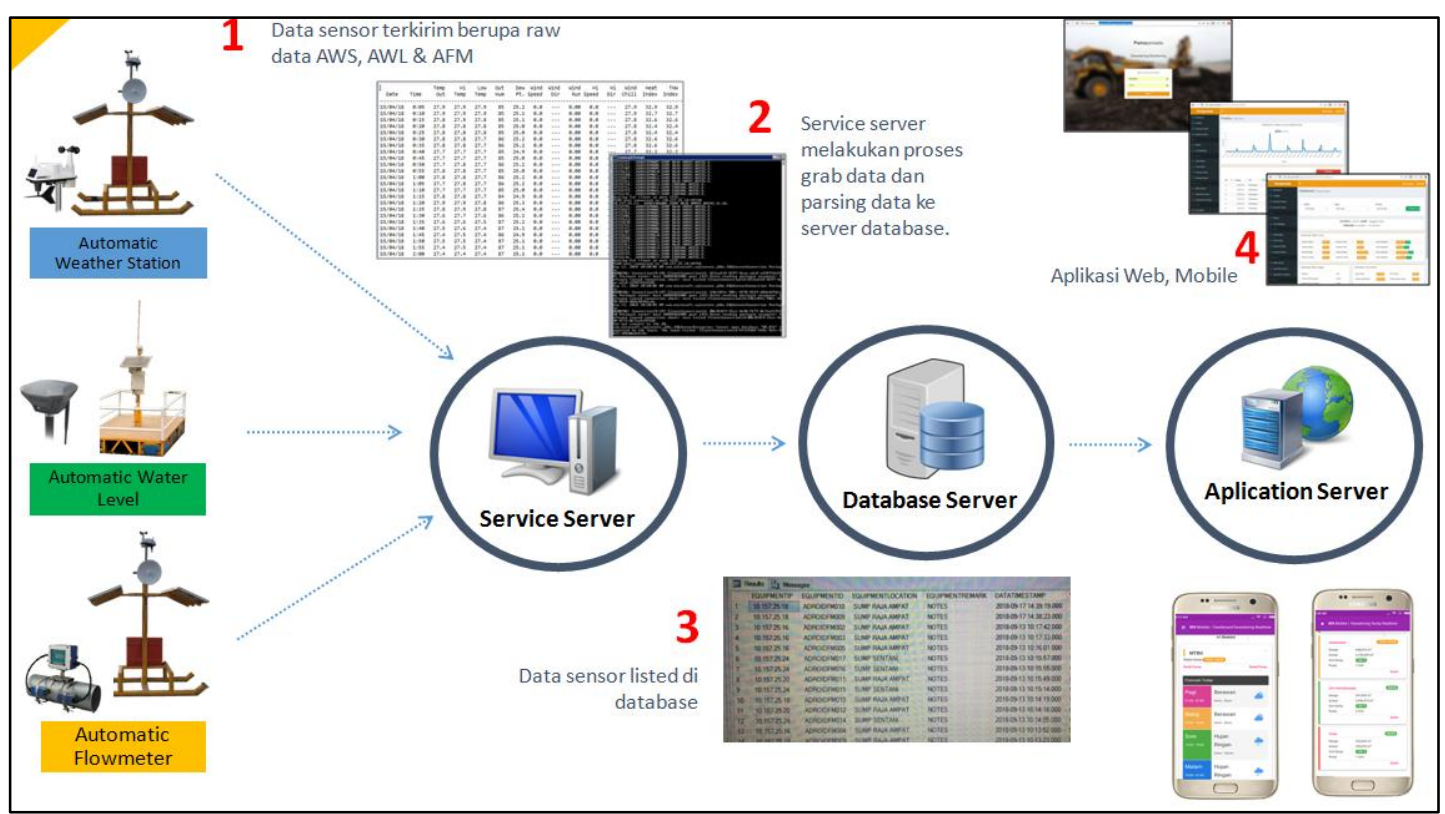

Gambar 9. Digitalisasi monitoring dewatering "IDS"

\section{KESIMPULAN}

Berdasarkan hasil implementasi IDS sebelum dan sesudah memanfaatkan teknologi Weather Station, Automatic Flowmeter, Automatic Water Level yang telah dilakukan, dapat diambil kesimpulan sebagai berikut:

a. Automatisasi proses dewatering sebagai alat bantu monitoring dewatering sangat bermanfaat. Tim Engineering, Tim Pit Service dan Management dapat melakukan monitoring dewatering dengan lebih mudah dan lebih cepat dengan monitoring pada media Smartphone.

b. Dengan monitoring dewatering secara real time tindakan perbaikan (corrective action).

c. dapat segera dilaksanakan sehingga kerugian dapat diminimalisir.

d. Akurasi data monitoring dewatering yang dihasilkan dari digitalisasi berdampak pada pembuatan perencanaan yang cepat dan lebih akurat.

e. IDS meningkatkan awareness seluruh pihak terkait untuk mencapai Status Sump yang "AMAN".

\section{UCAPAN TERIMA KASIH}

Atas terlaksananya penelitian "IDS" kami mengucapkan terima kasih kepada PT. Pamapersada Nusantara secara khusus untuk Engineering Division team dan Technical Service Engineer Team yang telah membantu penyediaan data, infrastruture untuk peneltian ini. 


\section{DAFTAR PUSTAKA}

Rinaldi, Aris,. November 2016. Hydrogeological Decision Analysis : Sump Optimization at an Open Pit Mine:Bandung.

Data Spesifikasi Alat Pompa Multiflo, data diperoleh melalui situs internet:https://www. Globalweir.com

Data Spesifikasi Alat Ukur Curah Hujan Davis, data diperoleh melalui situs internet:https://www.davisinstruments.com 
PROSIDING TPT XXVIII PERHAPI 2019 